\title{
Sex differences in the association between asthma incidence and modifiable risk factors in Korean middle-aged and older adults: NHIS-HEALS 10-year cohort
}

Susan Park', Sun-Young Jung ${ }^{2}$ and Jin-Won Kwon ${ }^{1 *}$

\begin{abstract}
Background: This study investigated the sex-specific incidence of asthma and the effects of modifiable risk factors, particularly obesity, on asthma incidence among middle-aged and older individuals in Korea.

Methods: We used data from the National Health Insurance Service-Health Screening Cohort (NHIS-HEALS), which includes health examinees aged 40-79years in 2002-2003. In total, 459,529 participants with baseline anthropometric measurements were followed-up for 10 years and the development of asthma was evaluated (2004-2013). For subgroup analysis, 246,019 participants who had body mass index (BMI) and waist circumference (WC) measurements taken in 2008-2009 were included in the analysis of the asthma incidence for 2010-2013. Factors associated with asthma were analysed using Cox proportional hazard models.

Results: The cohort comprised 4,248,813 (men, 2,358,541; women, 1,890,272) person-years of follow-up for 2004-2013. The asthma incidence was 10.58 and 15.03 per 1000 person-years for men and women, respectively. Asthma incidence increased with age, notably so in men. Obesity based on the baseline BMI was significantly associated with asthma development in both sexes (men, $H R=1.23$, 95\% confidence interval $(C l)=1.13-1.34$; women, $H R=1.4095 \%$ $\mathrm{Cl}=1.32-1.48$ ). High WC was also related to asthma incidence in both sexes with statistical significance (men, $\mathrm{HR}=1.34,95 \% \mathrm{Cl}=1.16-1.57$; women, $\mathrm{HR}=1.1995 \% \mathrm{Cl}=1.03-1.37)$. Analysis of the combined effects of $\mathrm{BMI}$ and WC showed that men had a higher asthma risk in the group with both general obesity and abdominal obesity than in the group with non-abdominal obesity and normal BMI. However, obese women had a higher risk of asthma regardless of abdominal obesity. Similarly, smoking was associated with asthma in both sexes but drinking and physical activity showed different associations between the sexes.

Conclusions: Our results revealed that asthma incidence was substantially high at old age and lifestyle factors were associated with asthma development. Practical strategies including weight control and healthy lifestyle modification are required to prevent asthma in older people.
\end{abstract}

Keywords: Body mass index, Waist circumference, Asthma, Older adults

\footnotetext{
* Correspondence: jwkwon@knu.ac.kr

${ }^{1}$ College of Pharmacy and Research Institute of Pharmaceutical Sciences,

Kyungpook National University, 80 Daehak-ro, Daegu 41566, South Korea

Full list of author information is available at the end of the article
}

(c) The Author(s). 2019 Open Access This article is distributed under the terms of the Creative Commons Attribution 4.0 International License (http://creativecommons.org/licenses/by/4.0/), which permits unrestricted use, distribution, and reproduction in any medium, provided you give appropriate credit to the original author(s) and the source, provide a link to the Creative Commons license, and indicate if changes were made. The Creative Commons Public Domain Dedication waiver (http://creativecommons.org/publicdomain/zero/1.0/) applies to the data made available in this article, unless otherwise stated. 


\section{Background}

Asthma in older adults is a serious health problem, particularly in conjunction with the rapid aging of society [1]. The prevalence of asthma among older adults is substantially high (range, 4.5-12.7\%) [2, 3], even though asthma is more likely to be underdiagnosed and undertreated [4]. Moreover, older patients with asthma are more likely to be hospitalised and have a higher death rate than their younger counterparts $[5,6]$. Consequently, the burden of asthma increases with age in adult individuals and this is more apparent among elderly individuals $[7,8]$. Nevertheless, basic epidemiological data on the prevention and treatment of asthma among older adults are limited [2, 9].

Lifestyle factors such as smoking, drinking and physical activity are reportedly modifiable risk factors for adult asthma. However, there are inconsistencies in their associations according to sex [10]. Two previous longitudinal studies reported that physical activity was not associated with asthma incidence among middle-aged and older women [11, 12], whereas a Finnish cohort study showed that physical activity had a protective effect on asthma onset in men [10]. Furthermore, previous studies have indicated the possibility of sex differences in the effects of smoking and drinking on asthma development $[13,14]$, but the available population-based studies are insufficient, particularly for older people.

Obesity is another well-known modifiable risk factor for asthma [15-27]; however, age- and sex-related differences in the obesity-asthma association have not been fully elucidated. Although the adverse effects of high body mass index (BMI) were more evident among elderly subjects than young and middle-aged participants in a recent study [15], data on the association between obesity and asthma in older adults remains sparse. In terms of sex, some cohort studies have shown sexspecific associations between high BMI and asthma development in women [16-21] and men [22]. However, others have reported a similar relationship between BMI and asthma for both sexes [23-27].

BMI is a commonly employed tool for measuring obesity in adults. However, it cannot reflect the distributions of lean mass and fat in body compartments, which are significantly influenced by age and sex [28, 29]. Alternatively, waist circumference (WC) is used as a stronger predictor of visceral adipose tissue (VAT), which is more metabolically active than fat at other sites [30, 31] compared to BMI [32, 33]. To this end, using both WC and BMI to measure obesity is recommended [34, 35]. However, few studies have taken advantage of both BMI and WC to assess the risk of asthma [36-39].

Therefore, this study aimed to assess the asthma incidence according to both age and sex while also investigating the sex-specific associations between modifiable risk factors and asthma incidence in Korean middleaged and older adults. In particular, the association between obesity and asthma using individual and combined measurements of BMI and WC was explored.

\section{Methods \\ Study participants}

The National Health Insurance Service-Health Screening Cohort (NHIS-HEALS) is a cohort comprising a $10 \%$ random sample $(n=514,866)$ from all health-screened participants aged 40-79 years from 2002 to 2003 [40]. The NHIS provides biennial health screening programmes (annually for manual workers) for insured individuals and their dependents aged $\geq 40$ years. This NHIS covers approximately $97 \%$ (Medicaid, approximately 3\%) of Korea's entire population and the participation rate among the eligible population in the NHIS health screening programme was $74.8 \%$ in 2014 [40]. The screening programme included anthropometric measurements, laboratory assessments of blood and urine samples, and the administration of questionnaires about health behaviours. The NHIS-HEALS contains data on health screening, insurance eligibility status, household income, demographic information, medical treatments and mortality information, such as the cause and date of death, for 2002-2013.

Except for participants without BMI measurements ( $n=516)$, the number of participants who had their BMIs measured from 2002 to 2003 was 514,350. Among them, participants who had extreme BMI values $(n=17)$ and those who had a diagnosis of asthma $(n=53,779)$ or had died $(n=1025)$ in 2002-2003 were excluded. Finally, 459,529 participants in total were analysed as the baseline study sample.

The measurement of WC was first included in NHISHEALS in 2008. Therefore, we selected 246,019 out of 459,529 participants for subgroup analysis to investigate the combined effects of BMI and WC on asthma after excluding participants with missing WC or BMI values in 2008-2009 $(n=91,391)$ and those who had an asthma diagnosis $(n=106,274)$ or had died $(n=15,845)$ before the follow-up period (Fig. 1).

In the sample selection process, we excluded patients with an asthma diagnosis regardless of drug prescriptions to rule out the possibility of pre-existing asthma before the follow-up period.

\section{Measures}

A newly diagnosed asthma case was defined as someone who has both an asthma diagnosis and a prescription for asthma drugs to increase diagnosis accuracy [41]. Asthma diagnoses were assessed using the J45 or J46 ICD-10 codes (International Classification of Disease, 10th Edition) in medical treatment data. Asthma drugs 


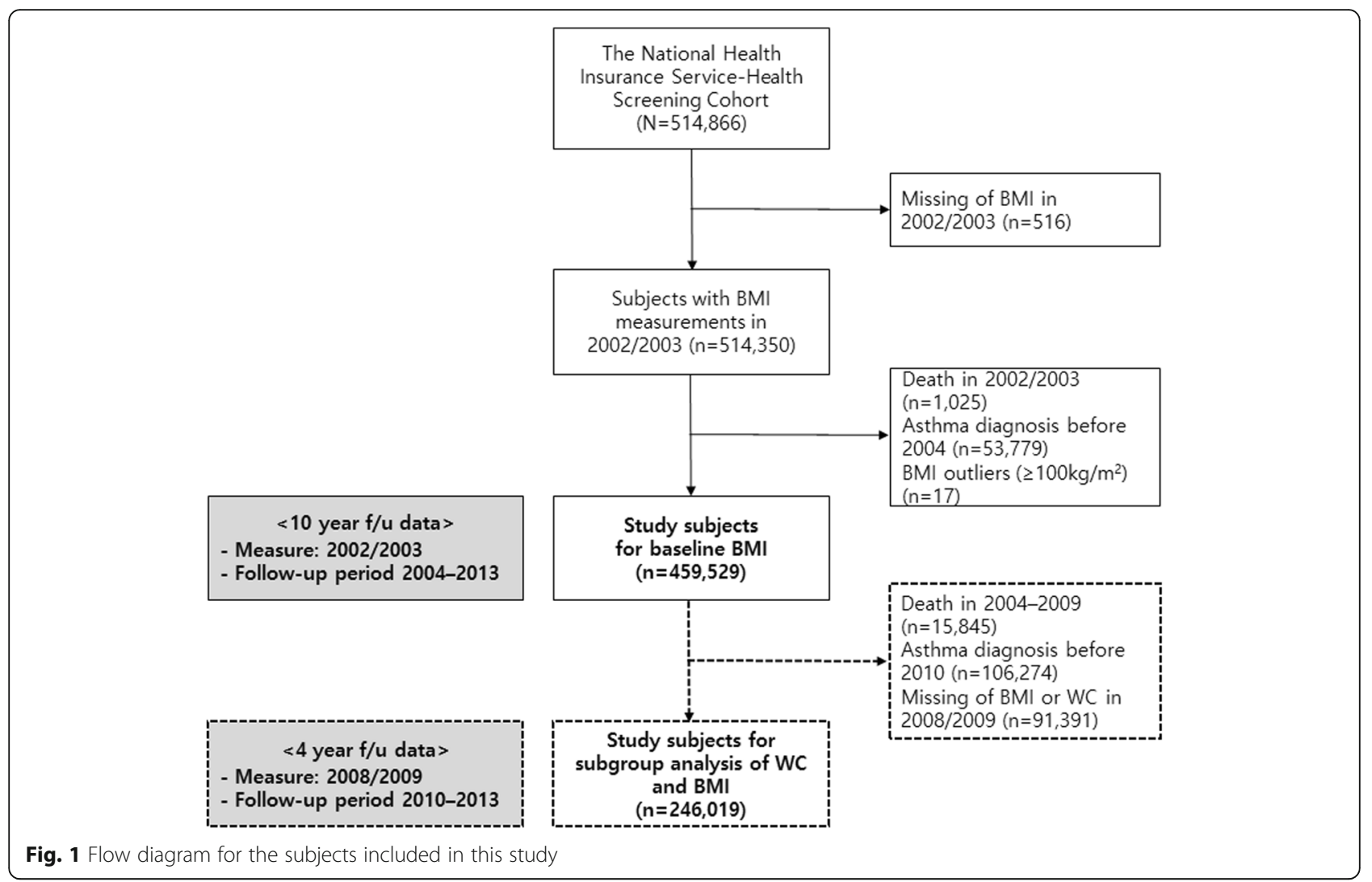

included inhaled beta-agonists, inhaled corticosteroids and leukotriene receptor antagonists according to the Global Initiative for Asthma Guidelines.

Anthropometric indexes including height, weight and WC were measured in a standardised manner by trained nurses at each examination [34]. General obesity was determined from BMI, calculated as weight in kilograms divided by the square of height in meters, and the measurements were classified into five groups based on the obesity criteria for Asians: 1 ) $<18.5 \mathrm{~kg} / \mathrm{m}^{2}$ (underweight), 2) 18.5 to $<23 \mathrm{~kg} / \mathrm{m}^{2}$ (normal), 3) 23 to $<25 \mathrm{~kg} / \mathrm{m}^{2}$ (overweight), 4) 25 to $<30 \mathrm{~kg} / \mathrm{m}^{2}$ (obesity) and 5) $\geq 30$ $\mathrm{kg} / \mathrm{m}^{2}$ (severe obesity) [42]. The measured WC was used to assess abdominal obesity, which was defined as WC > $90 \mathrm{~cm}$ in men and $>85 \mathrm{~cm}$ in women [43]. The combined variable of BMI and WC was categorised into six groups: 1) no abdominal obesity \& underweight/normal BMI, 2) no abdominal obesity \& overweight BMI, 3) no abdominal obesity \& obese BMI, 4) abdominal obesity \& underweight/normal BMI, 5) abdominal obesity \& overweight BMI and 6) abdominal obesity \& obese BMI.

Household income was divided into three groups (low: grade $0-4$, middle: grade $5-8$ and high: grade $9-10$ ), based on 11 levels of insurance fees in the NHIS insurance eligibility data. Information on health behaviours such as smoking, drinking and physical activity was collected via questionnaires. Smoking status was categorised as current smoker, past smoker and non-smoker using the question "Do you smoke cigarettes now?" with three levels of responses: 1) never smoked, 2) smoked in the past, but not now and 3) currently smoke. The questionnaires regarding drinking and physical activity were assessed based on the frequency of behaviours and consisted of five levels: 1 ) none, 2) 2-3 times per month, 3) 1-2 times per week, 4) 3-4 times per week and 5) almost every day. Using these levels, the variables were categorised into none, $<2$ times per week and $>3$ times per week. The insurance types were: self-employed insured, employed insured and medical aid beneficiary.

\section{Analysis}

The development of asthma was monitored from 1 January 2004 to 31 December 2013 for the analysis of baseline BMI and health behaviours. For subgroup analysis on both BMI and WC, the follow-up for asthma incidence started on 1 January 2010 and ended on 31 December 2013. The participants who had medical records with an asthma diagnosis code (J45 or J46) before starting the follow-up (1 January 2004 for the main analysis and 1 January 2010 for subgroup analysis) were excluded in the analysis to confirm the preexistence of asthma. Asthma incidence was the end-point for all analyses and participants who were dead or did not have an asthma diagnosis by 31 December 2013 were censored. 
First, the sample size and proportion of each category were calculated to check the distribution of the baseline population. We analysed the asthma incidence rates according to sex and age groups, which were calculated by dividing the number of new cases of asthma by the summing person-years of observation in each category during the follow-up period. Uni- and multi-variable hazard ratios (HRs) and their 95\% confidence intervals (CIs) were estimated using Cox proportional hazard models to evaluate the effects of baseline BMI on asthma incidence. In the subgroup analysis, HRs were estimated to explore the effects of BMI and WC both separately and in combination in 2008/2009 on the development of asthma. Multivariable models were adjusted for age, insurance type, household income, smoking, drinking and physical activity at the baseline. To reduce data loss, missing values for smoking, drinking and physical activity were included in the analysis as a separate category named 'unknown'.

Sensitivity analysis with various follow-up times was conducted to evaluate the induction period for obesityinduced asthma. We compared the effects of the baseline characteristics on the asthma incidence using two and four years of induction time before the asthma follow-up.

All analyses of men and women were conducted separately to explore the association between BMI and asthma incidence in terms of sex. Statistical analyses were performed using SAS version 9.4 (SAS Institute Inc., Cary, NC, USA).

\section{Results}

The cohort comprised 459,529 participants (men, 254, 643; women, 204,886) with 9.2 years of mean follow-up time. The study period counted as $4,248,813$ personyears (men, 2,358,541 person-years; women, 1,890,272 person-years). During the observation period, 24,959 men and 28,412 women developed asthma. The distributions of the characteristics at the baseline are presented according to sex in Table 1 . The mean ages at the baseline were 51.5 and 53.1 years in men and women, respectively. A higher prevalence of current smoking (men, 40.6\%; women, 2.6\%) and alcohol consumption ( $\geq 3$ times a week: men, 19.4\%; women, $1.8 \%$ ) was observed more in men than in women. Moreover, the proportions of frequent physical activity $(\geq 3$ times a week: men, 20.1\%; women, 15.9\%) and obesity (BMI $\geq 25 \mathrm{~kg} /$ $\mathrm{m}^{2}$ : men, 35.5\%; women, 33.6\%) were higher in men than in women.

Figure 2 shows the incidence rates of asthma based on age and BMI by sex. The overall incidence rates were 10.6 and 15.0 per 1000 person-years in men and women, respectively. The asthma incidence rates were higher among women than among men for those aged 40-60 years. Although the incidence of asthma increased with
Table 1 Baseline characteristics of study participants by sex

\begin{tabular}{|c|c|c|}
\hline & Men & Women \\
\hline & n (\%) & n (\%) \\
\hline Total & 254,643 & 204,886 \\
\hline \multicolumn{3}{|l|}{ Age } \\
\hline $40-49$ & $128,281(50.4)$ & $90,458(44.2)$ \\
\hline $50-59$ & $71,765(28.2)$ & $58,433(28.5)$ \\
\hline $60-69$ & $43,079(16.9)$ & $42,448(20.7)$ \\
\hline$\geq 70$ & $11,518(4.5)$ & $13,547(6.6)$ \\
\hline \multicolumn{3}{|l|}{ Household income } \\
\hline Low & $62,487(24.5)$ & $75,521(36.9)$ \\
\hline Medium & $97,249(38.2)$ & $70,298(34.3)$ \\
\hline High & $94,907(37.3)$ & $59,067(28.8)$ \\
\hline \multicolumn{3}{|l|}{ Insurance type } \\
\hline Self-employed insured & $79,514(31.2)$ & $94,455(46.1)$ \\
\hline Employed insured & $174,968(68.7)$ & $110,128(53.8)$ \\
\hline Medical aid beneficiary & $161(0.1)$ & $303(0.2)$ \\
\hline \multicolumn{3}{|l|}{ BMl } \\
\hline Underweight $\left(<18.5 \mathrm{~kg} / \mathrm{m}^{2}\right.$ ) & $5548(2.2)$ & $4647(2.3)$ \\
\hline Normal $\left(18.5-<23 \mathrm{~kg} / \mathrm{m}^{2}\right)$ & $86,195(33.9)$ & $77,837(38.0)$ \\
\hline Overweight $\left(23-<25 \mathrm{~kg} / \mathrm{m}^{2}\right)$ & $72,614(28.5)$ & $53,585(26.2)$ \\
\hline Obesity $(25-<30$ kg/m²) & $85,063(33.4)$ & $61,638(30.1)$ \\
\hline Severe obesity $\left(\geq 30 \mathrm{~kg} / \mathrm{m}^{2}\right)$ & $5223(2.1)$ & $7179(3.5)$ \\
\hline \multicolumn{3}{|l|}{ Smoking status } \\
\hline Unknown & $11,751(4.6)$ & $7766(3.8)$ \\
\hline Never smoker & $101,698(39.9)$ & $189,987(92.7)$ \\
\hline Past smoker & $37,778(14.8)$ & $1825(0.9)$ \\
\hline Current smoker & $103,416(40.6)$ & $5308(2.6)$ \\
\hline \multicolumn{3}{|l|}{ Alcohol consumption } \\
\hline Unknown & $3612(1.4)$ & $5007(2.4)$ \\
\hline None & 85,986 (33.8) & $164,513(80.3)$ \\
\hline$<$ Twice a week & $115,545(45.4)$ & $31,637(15.4)$ \\
\hline$\geq$ Three times a week & $49,500(19.4)$ & $3729(1.8)$ \\
\hline \multicolumn{3}{|l|}{ Physical activity } \\
\hline Unknown & $7844(3.1)$ & $6031(2.9)$ \\
\hline None & $121,735(47.8)$ & $133,098(65.0)$ \\
\hline$<$ Twice a week & $73,988(29.1)$ & $33,089(16.2)$ \\
\hline$\geq$ Three times a week & $51,076(20.1)$ & $32,668(15.9)$ \\
\hline
\end{tabular}

$\mathrm{BMI}=$ Body Mass Index

Baseline characteristics were measured in 2002/2003

age for both sexes, the increase was much steeper for men than for women. Therefore, the incidence rate was higher among men than women in individuals aged $\geq 70$ years. In the BMI categories, the incidence of asthma was U-shaped in men. Underweight subjects had the highest incidence of asthma (16.6 per 1000 person-years) among the BMI ranges and the second-highest incidence 

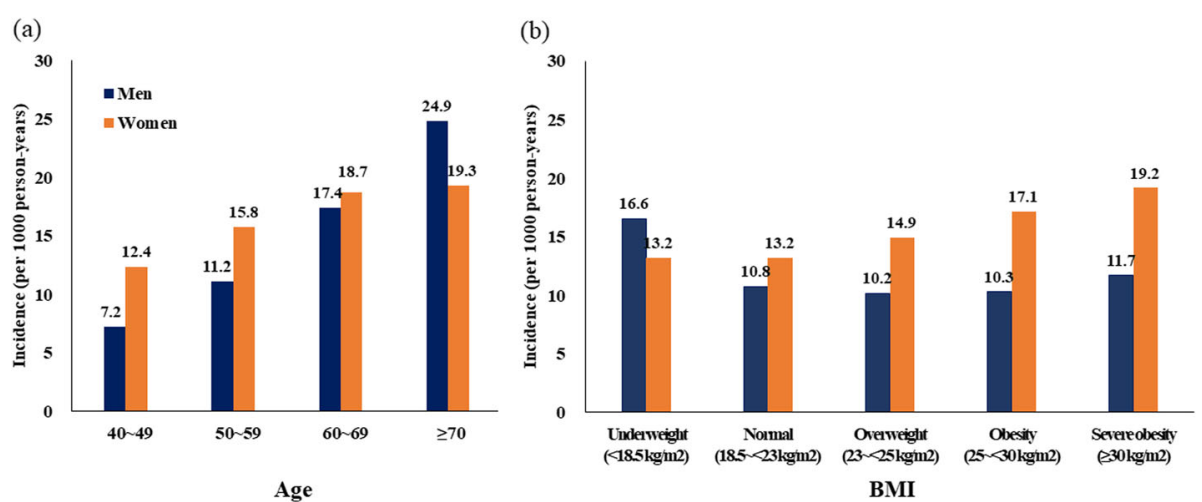

Fig. 2 The asthma incidence per 1000 person-years during the 10-year follow-up period (2004-2013). (a) Asthma incidence by age and sex; (b) asthma incidence by BMI and sex. ${ }^{*}$ An asthma case was defined as a person with an ICD-10 diagnosis code J45 or J46 and a prescription for inhaled beta-agonists, inhaled corticosteroid, or leukotriene receptor antagonist in the claims database

was observed in the severe obesity group (11.7 per 1000 person-years). Meanwhile, the incidence of asthma increased monotonically with BMI in women and the highest incidence was observed in severely obese women (19.2 per 1000 person-years).

Table 2 presents the uni- and multi-variable HRs for the asthma incidence according to various risk factors based on sex. Severe obesity based on BMI was a common risk factor for asthma incidence in both sexes (BMI $\geq 30 \mathrm{~kg} / \mathrm{m}^{2}$, men $\mathrm{HR}=1.23,95 \% \mathrm{CI}: 1.13-1.34$; women, $\mathrm{HR}=1.40$, 95\% CI: 1.32-1.48). In women, BMI-based underweight status was associated with a lower risk of asthma compared to normal weight, whereas underweight men had an increased risk of asthma (men, HR = 1.32, 95\% CI: $1.23-1.43$; women, $\mathrm{HR}=0.94,95 \% \mathrm{CI}$ : $0.87-1.03)$.

Current smoking was a significant risk factor for asthma development in both sexes (men: $\mathrm{HR}=1.07 ; 95 \%$ $\mathrm{CI}=1.04-1.10$; women: $\mathrm{HR}=1.42 ; 95 \% \mathrm{CI}=1.33-1.51$ ). Men who drank had a lower HR for asthma than those who did not $(\mathrm{HR}=0.86 ; 95 \% \mathrm{CI}=0.83-0.90)$. However, a non-significant effect was observed in women. Physical activity had a preventive effect on the development of asthma in men $(\mathrm{HR}=0.96 ; 95 \% \mathrm{CI}=0.93-0.99)$, whereas it was a risk factor for women $(\mathrm{HR}=1.05 ; 95 \% \mathrm{CI}=$ $1.02-1.08)$.

Table 3 presents the adjusted HRs for asthma development according to the individual and combined variables of BMI (general obesity) and WC (abdominal obesity). The HRs for obesity measured by BMI in 2008/2009 were similar to those for obesity measured by BMI in $2002 / 2003$ in the main analysis $\left(B M I \geq 30 \mathrm{~kg} / \mathrm{m}^{2}\right.$, men $\mathrm{HR}=1.23$, 95\% CI: $1.05-1.45$; women, $\mathrm{HR}=1.28,95 \%$ CI: 1.12-1.47). High WC was significantly associated with asthma incidence in both sexes. In the results for the combined variable of BMI and WC, women showed similar associations for general obesity measured by BMI and asthma regardless of abdominal obesity. However, an increased risk for asthma was observed in for overweight/obesity as measured by BMI only in men with abdominal obesity. Men without abdominal obesity did not show an increased risk of asthma even in obesity based on BMI.

Sensitivity analysis was conducted using two- and four-year lag times before the follow-up for asthma development. The association patterns between BMI and asthma were similar, although HRs were slightly decreased (Additional file 1: Table S1).

\section{Discussion}

We defined pre-existing asthma based on the diagnosis of asthma with ICD-10 codes (J45 or J46) regardless of drug prescription in the selection process for the study sample, whereas newly diagnosed asthma was defined using both asthma diagnosis and drug prescription during the follow-up period for asthma incidence. A previous study by Dombkowski et al. explored the accuracy of several case definitions for asthma based on the claims database [41]. They compared the positive predictive values of different case definitions including participants taking one or more asthma medications ( $\mathrm{Rx}$ cases) and those who were not taking asthma medications despite having an asthma diagnosis (Dx cases). They reported a higher accuracy for the definition of $\mathrm{Rx}$ cases than those of Dx cases. Thus, when we focus on the accurate detection of new asthma diagnoses, it may be more appropriate to consider both drug prescription and asthma diagnosis as a definition for asthma. However, it is more important to fully exclude patients with underlying asthma from the sample selection process. If there were patients who had not been prescribed drugs due to the temporary improvement of symptoms, preexisting asthma cannot be detected using the same definition as for newly diagnosed asthma. Therefore, two 
Table 2 Hazard ratios for asthma during a 10-year follow-up (2004-2013) according to age, economic status, health behaviours and BMl by sex

\begin{tabular}{|c|c|c|c|c|c|c|}
\hline & \multicolumn{3}{|l|}{ Men } & \multicolumn{3}{|c|}{ Women } \\
\hline & Case & Univariable Model & MultivariableModel & Case & Univariable Model & MultivariableModel \\
\hline & & HR $(95 \%$ Cl) & HR $(95 \%$ Cl) & & HR (95\% Cl) & HR $(95 \%$ Cl) \\
\hline \multicolumn{7}{|l|}{ Age } \\
\hline $40-49$ & 8924 & - & - & 10,602 & - & - \\
\hline $50-59$ & 7451 & $1.55(1.51-1.60)$ & $1.53(1.48-1.58)$ & 8547 & $1.28(1.24-1.32)$ & $1.24(1.21-1.28)$ \\
\hline $60-69$ & 6466 & $2.47(2.39-2.55)$ & $2.38(2.30-2.46)$ & 7119 & $1.53(1.49-1.58)$ & $1.48(1.44-1.53)$ \\
\hline$\geq 70$ & 2118 & $3.70(3.53-3.88)$ & $3.46(3.30-3.64)$ & 2144 & $1.61(1.54-1.69)$ & $1.58(1.51-1.66)$ \\
\hline \multicolumn{7}{|l|}{ Insurance type } \\
\hline Self-employed insured & 8927 & - & - & 13,309 & - & - \\
\hline Employed insured & 16,000 & $0.78(0.76-0.80)$ & $0.92(0.89-0.94)$ & 15,045 & $0.96(0.94-0.98)$ & $1.00(0.97-1.02)$ \\
\hline Medical aid beneficiary & 32 & $2.20(1.56-3.12)$ & $1.69(1.20-2.40)$ & 58 & $1.51(1.17-1.95)$ & $1.38(1.06-1.78)$ \\
\hline \multicolumn{7}{|l|}{ Household income } \\
\hline Low & 6913 & - & - & 10,520 & - & - \\
\hline Medium & 9193 & $0.82(0.80-0.85)$ & $0.95(0.92-0.98)$ & 9756 & $0.99(0.96-1.02)$ & $0.99(0.96-1.01)$ \\
\hline High & 8853 & $0.80(0.77-0.82)$ & $0.97(0.94-1.00)$ & 8136 & $0.98(0.95-1.01)$ & $1.00(0.98-1.03)$ \\
\hline \multicolumn{7}{|l|}{ BMI } \\
\hline Underweight $\left(<18.5 \mathrm{~kg} / \mathrm{m}^{2}\right)$ & 763 & $1.57(1.46-1.69)$ & $1.32(1.23-1.43)$ & 554 & $1.02(0.94-1.10)$ & $0.94(0.87-1.03)$ \\
\hline Normal $\left(18.5-<23 \mathrm{~kg} / \mathrm{m}^{2}\right)$ & 8494 & - & - & 9571 & & - \\
\hline Overweight $\left(23-<25 \mathrm{~kg} / \mathrm{m}^{2}\right)$ & 6910 & $0.94(0.91-0.97)$ & $1.00(0.96-1.03)$ & 7390 & $1.14(1.11-1.17)$ & $1.11(1.07-1.14)$ \\
\hline Obesity $\left(25-<30 \mathrm{~kg} / \mathrm{m}^{2}\right)$ & 8223 & $0.95(0.93-0.98)$ & $1.04(1.01-1.07)$ & 9657 & $1.31(1.27-1.34)$ & $1.24(1.21-1.28)$ \\
\hline Severe obesity $\left(\geq 30 \mathrm{~kg} / \mathrm{m}^{2}\right)$ & 569 & $1.08(1.00-1.18)$ & $1.23(1.13-1.34)$ & 1240 & $1.50(1.42-1.58)$ & $1.40(1.32-1.48)$ \\
\hline \multicolumn{7}{|l|}{ Smoking status } \\
\hline Unknown & 1158 & $0.95(0.90-1.01)$ & $1.05(0.98-1.13)$ & 1093 & $1.03(0.97-1.09)$ & $1.00(0.92-1.10)$ \\
\hline Never smoker & 10,474 & - & - & 26,081 & - & - \\
\hline Past smoker & 3803 & $0.97(0.94-1.01)$ & $1.11(1.07-1.15)$ & 269 & $1.09(0.97-1.23)$ & $1.10(0.98-1.24)$ \\
\hline Current smoker & 9524 & $0.89(0.87-0.92)$ & $1.07(1.04-1.10)$ & 969 & $1.43(1.34-1.53)$ & $1.42(1.33-1.51)$ \\
\hline \multicolumn{7}{|l|}{ Drinking status } \\
\hline Unknown & 369 & $0.89(0.80-0.99)$ & $0.85(0.76-0.96)$ & 728 & $1.05(0.97-1.13)$ & $1.00(0.90-1.12)$ \\
\hline None & 9749 & - & - & 22,950 & - & - \\
\hline$<$ Twice a week & 10,040 & $0.74(0.71-0.76)$ & $0.87(0.84-0.89)$ & 4180 & $0.93(0.90-0.97)$ & $0.99(0.95-1.02)$ \\
\hline$\geq$ Three times a week & 4801 & $0.85(0.82-0.88)$ & $0.86(0.83-0.90)$ & 554 & $1.07(0.98-1.16)$ & $1.05(0.96-1.14)$ \\
\hline \multicolumn{7}{|l|}{ Physical activity } \\
\hline Unknown & 798 & $0.97(0.90-1.04)$ & $1.07(0.98-1.16)$ & 866 & $1.04(0.97-1.11)$ & $1.04(0.96-1.13)$ \\
\hline None & 12,572 & - & - & 18,364 & - & - \\
\hline$<$ Twice a week & 6518 & $0.82(0.80-0.85)$ & $0.96(0.93-0.99)$ & 4503 & $0.97(0.94-1.01)$ & $1.02(0.99-1.06)$ \\
\hline$\geq$ Three times a week & 5071 & $0.94(0.91-0.97)$ & $0.96(0.93-0.99)$ & 4679 & $1.03(1.00-1.07)$ & $1.05(1.02-1.08)$ \\
\hline
\end{tabular}

different definitions of asthma were used to increase the diagnosis accuracy and exclude the possibility of underlying asthma prevalence.

Asthma incidence increased with age in both sexes and the increasing trend in terms of age was more prominent among men than among women. In addition, earlier studies revealed a higher asthma incidence among older individuals than among middle-aged individuals, particularly among men. For example, the asthma incidence in a Canadian population was 3.7 (2.8) and 4.2 (3.2) per 1000 person-years in individuals aged 40-69 and $\geq 70$ years for 2000-2001 (2004-2005), respectively. The increment of the asthma incidence between middleaged and elderly individuals was higher among men than 
Table 3 Subgroup analysis for asthma during four-year follow-up (2010-2013) according to body mass index and waist circumference by sex

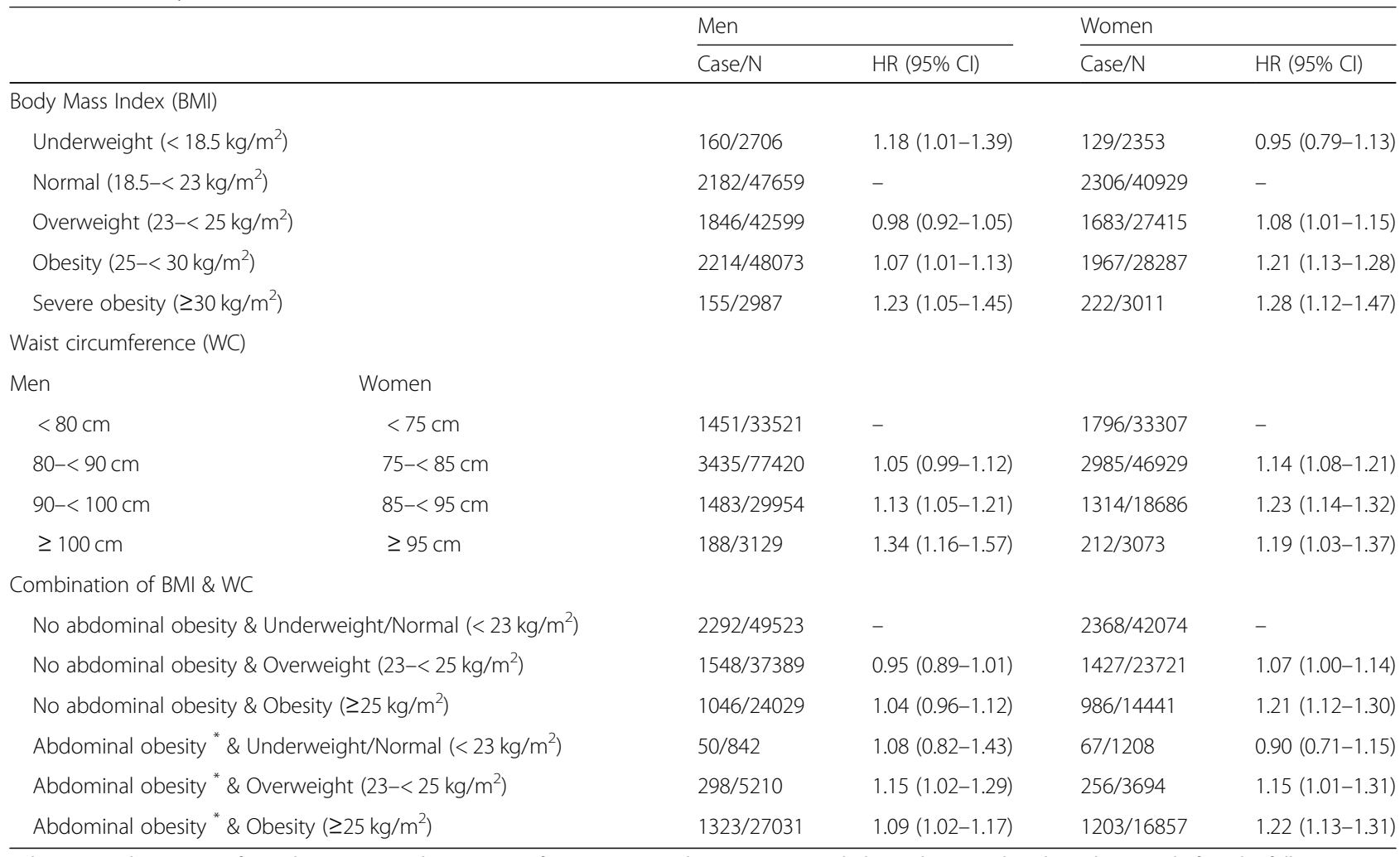

Subgroup analysis was performed using BMI and waist circumference measured in 2008/2009 excluding subjects with asthma diagnosis before the follow-up period. Separate models were developed for BMI, WC and the combination of BMI and WC after adjusting for age, insurance type, household income, smoking, drinking and physical activity

* Abdominal obesity was defined as waist circumference $>100 \mathrm{~cm}$ in men or $95 \mathrm{~cm}$ in women

among women (men, 40-69 years: 2.2 and $\geq 70$ years: 3.1; women, $40-69$ years: 3.3 and $\geq 70$ years: 3.4 ; unit: per 1000 people) [44]. The rapid increase in asthma incidence among men might be related to sex hormones associated with the functions of epithelial cells. For example, progesterone inhibits the beat frequency of cilia and its receptor is expressed in the airway epithelium, which may affect mucociliary clearance during the menstruation cycle in women [45]. Indeed, asthma is more prevalent and severe after puberty in women [46, 47]. Likewise, menopausal women had a significantly lower risk for asthma than premenopausal women [48]. Therefore, our result that the incidence of asthma among older men was relatively higher than among older women might be explained by the effect of sex hormones in middle-aged and older individuals.

Although our results showed that the asthma incidence differed between men and women, the deleterious effects of obesity according to BMI on asthma were similar for both sexes. Several prospective studies have shown sex-specific associations between obesity in terms of BMI and asthma [18, 21, 22]. However, a metaanalysis of seven cohort studies with heterogeneous results concluded that obese individuals are almost at a twofold higher risk for asthma than those with normal weight in both sexes [49]. Although the strength of the obesity effect $\left(B M I \geq 30 \mathrm{~kg} / \mathrm{m}^{2}\right)$ on asthma was slightly lower (20-40\% increased risk) compared to the results of previous studies (OR or RR 1.5-3.0) [16-25, 27, 50], a cautious comparison should be made because of the inconsistent reference category, different races (Western vs. Asian) and participants' varying ages (mainly young to middle-aged adults vs. middle-aged and older adults). The findings in our study indicate that asthma is associated with obesity regardless of sex in middle-aged and older populations in Korea.

The underlying mechanism responsible for the association between obesity and asthma has not been fully elucidated. However, the following are several plausible relationships: $i$ ) systemic inflammation modulated by adipokines and adipose tissues, ii) mechanical changes in the respiratory system and iii) comorbidities. Adipose tissue secretes various pro- and anti-inflammatory adipokines that modulate inflammation [51]. An excess of pro-inflammatory adipokines (leptin, TNF- $\alpha$, IL-6, etc.) may be responsible for the association between asthma and obesity. Pro-inflammatory molecules such as TNF- $\alpha$ and IL- 6 inhibit the production of adiponectin and 
typical anti-inflammatory adipokines. The serum concentrations of pro-inflammatory adipokines increased with obesity, whereas serum adiponectin concentrations were lower in obese individuals $[52,53]$. Thus, chronic systemic inflammation in obese individuals may increase their susceptibility to airway obstruction and bronchial hyper-responsiveness [54]. In addition, obesity causes adverse mechanical changes in lung volume and airway resistance due to increased intra-abdominal pressure, reduced diaphragm movement and changes in chest-wall properties [55]. Finally, common comorbidities such as obstructive sleep apnoea or gastroesophageal reflux disease could also affect the association between obesity and asthma [56].

We observed a sex difference in the association between underweight status and asthma incidence. In our results, underweight men based on BMI had a higher risk of asthma development than men in normal BMI ranges but the association was non-significant in women. Although the association between underweight status and asthma is still unclear, several empirical studies have shown a higher incidence of asthma in underweight subjects compared to the normal group [16, 19, 22, 27]. Moreover, underweight status has been associated with airway hyperresponsiveness (AHR), which is one of asthma's most important pathophysiological features [35, 57]. For example, a study involving Korean asthma patients revealed a negative association between BMI and AHR [57]. Another study demonstrated an elevated risk of AHR in low BMI men during a four-year follow-up period [35]. These studies suggest that underweight status may affect the development of asthma through a different pathway from obesity. However, the underweightasthma association remains to be defined in various populations with further studies, particularly regarding the sex difference.

It was found that the combined effect of abdominal obesity and BMI was also different between the sexes. Our results showed that only 'obese men with abdominal obesity' had a higher risk for asthma. 'Obese men without abdominal obesity' did not have an increased risk of asthma compared to those with 'normal weight without abdominal obesity'. Meanwhile, the risk for asthma in women was elevated in general obesity based on BMI regardless of waist size. These results might be because VAT distribution showed age and sex differences. Abdominal obesity is characterised as increased adipose tissue surrounding the intra-abdominal organs, which is known as VAT [28]. The incremental amount of VAT according to WC was greater in men than in women $[58,59]$. Furthermore, the slope of incremental VAT was steeper in older adults than in younger adults of either sex [59]. Therefore, the effect of abdominal obesity may be more prominent in older men.
Our study showed that health-related behaviours such as smoking, drinking and physical activity were associated with asthma risk. Similar to previous results [60, 61], smoking was a risk factor for asthma in our study because cigarette smoking can modify inflammation, which is associated with asthma [62]. Drinking was associated with a lower risk of asthma for women in our study, which is inconsistent with a previous study that found a U-shaped association with the risk for asthma [12]. This inconsistency in the association was attributed to differences in drinking behaviours, such as the preferred beverage type and number of consumed drinks, which can substantially change the association pattern. Our results showed that frequent exercise had a protective effect on asthma in men but the opposite effect in women. A previous meta-analysis also showed the inconsistency of the association between physical activity and asthma because of hidden effects including sex difference [10]. We only considered the frequency of physical activity, thus sex differences in the strength or duration of exercise could affect the results.

This study has several limitations. First, there was uncertainty regarding the accuracy of the definition of asthma using ICD-10 codes in the NHIS claims database. The differential diagnosis of chronic obstructive pulmonary disease (COPD) and asthma in primary care is challenging [63]. Thus, the asthma patients in our data could also have COPD. Although the positive predictive value of asthma in children was $>90 \%$ using the case definition of children prescribed one or more asthma medications in the claims database [41], we could not rule out the possibility that the number of patients with asthma may be either over- or underestimated. Second, we selected participants who had their BMI measured at the baseline and/or 2008-2009, which may have led to selection bias. However, the distributions of the baseline characteristics including obesity were similar to those in the original dataset and other nationally representative data such as the Korea National Health and Nutrition Examination Survey (data not shown) [64]. In addition, BMI in 2008-2009 was similar to the baseline BMI. Third, health-related behaviours such as smoking, drinking and physical activity were measured using self-reported questionnaires. The accuracy of the selfreported health behaviours has been explored previously and the results indicate the under-reporting of risky behaviours $[65,66]$. This limitation could lead to an underestimation of the effect of health-related behaviours on asthma.

\section{Conclusions}

This study showed an association between modifiable risk factors and asthma incidence in later life. Lifestyle factors including obesity, smoking, drinking and physical activity had independent effects on asthma incidence. Our results suggest that weight control and a healthy lifestyle can help prevent asthma. 


\section{Supplementary information}

Supplementary information accompanies this paper at https://doi.org/10. 1186/s12890-019-1023-3.

Additional file 1: Table S1. Sensitivity analysis for association between baseline BMI (2002-2003) and asthma incidence according to various lag time by sex. This analysis was performed to confirm the similarity of the associations between the risk factors and asthma when using different start dates.

\section{Abbreviations}

AHR: Airway Hyperresponsiveness; BMl: Body Mass Index; Cls: Confidence Intervals; HRs: Hazard Ratios; ICD-10: International Classification of Disease 10th Edition; NHIS-HEALS: National Health Insurance Service-Health Screening Cohort; VAT: Visceral Adipose Tissue; WC: Waist Circumference

\section{Acknowledgments}

This study used NHIS-HEALS data (NHIS-2017-2-465) provided by the NHIS. The authors declare no potential conflicts of interest with NHIS with respect to the authorship and/or publication of this article.

\section{Authors' contributions}

SP and JWK designed the study. SP and SYJ analysed the data and wrote the manuscript. All authors read and approved the final version of the manuscript.

\section{Funding}

This research was supported by the Basic Science Research Programme through the National Research Foundation of Korea (NRF) funded by the Ministry of Education, Science and Technology (NRF-2019R1I1A1A01046991). This funding source had no role in the design of this study and will not have any role during its execution, analyses, interpretation of the data, or decision to submit results.

\section{Availability of data and materials}

The NHIS-HEALS data are distributed to registered user through the official website of NHIS data sharing service (https://nhiss.nhis.or.kr/bd/ay/bdaya001 iv.do). After the evaluation of research proposal by NHIS review committee, registered user can receive special access privileges to the data.

\section{Ethics approval and consent to participate}

This study was approved by the institutional review board of Kyungpook National University (IRB number: KNU 2016-0077). After the National Health Insurance Service (NHIS) review committee reviewed the ethics approval and research proposal, we had the permission to use the NHIS-HEALS data (NHIS2017-2-465). The data were released after anonymisation and deidentification; therefore, informed consent could not be obtained from individual participants.

\section{Consent for publication}

Not applicable.

\section{Competing interests}

The authors declare that they have no competing interests.

\section{Author details}

${ }^{1}$ College of Pharmacy and Research Institute of Pharmaceutical Sciences, Kyungpook National University, 80 Daehak-ro, Daegu 41566, South Korea ${ }^{2}$ College of Pharmacy, Chung-Ang University, Seoul, Republic of Korea.

\section{Received: 28 February 2019 Accepted: 9 December 2019}

\section{Published online: 16 December 2019}

\section{References}

1. Gibson PG, McDonald VM, Marks GB. Asthma in older adults. Lancet (London, England). 2010;376(9743):803-13.

2. Yáñez A, Cho S-H, Soriano JB, Rosenwasser LJ, Rodrigo GJ, Rabe KF, Peters S, Niimi A, Ledford DK, Katial R, et al. Asthma in the elderly: what we know and what we have yet to know. World Allergy Organization J. 2014;7(1):8-8.

3. Hanania NA, King MJ, Braman SS, Saltoun C, Wise RA, Enright P, Falsey AA, Mathur SK, Ramsdell JW, Rogers L, et al. Asthma in the elderly: current understanding and future research needs: a report of a National Institute on Aging (NIA) workshop. J Allergy Clin Immunol. 2011;128(3 Suppl):S4-S24.

4. Enright PL, McClelland RL, Newman AB, Gottlieb DJ, Lebowitz MD. Underdiagnosis and undertreatment of asthma in the elderly. Cardiovascular Health Study Res Group Chest. 1999;116(3):603-13.

5. Moorman JE, Rudd RA, Johnson CA, King M, Minor P, Bailey C, Scalia MR, Akinbami LJ: National surveillance for asthma--United States, 1980-2004. Morbidity and mortality weekly report Surveillance summaries (Washington, DC : 2002) 2007, 56(8):1-54.

6. Moorman JE, Mannino DM. Increasing U.S. asthma mortality rates: who is really dying? The Journal of asthma : official journal of the Association for the Care of Asthma. 2001;38(1):65-71.

7. Nunes C, Pereira AM, Morais-Almeida M. Asthma costs and social impact. Asthma res practice. 2017;3:1

8. Lee YH, Yoon SJ, Kim EJ, Kim YA, Seo HY, Oh $1 \mathrm{H}$. Economic burden of asthma in Korea. Allergy asthma proceedings. 2011;32(6):35-40.

9. Song W-J, Kang M-G, Chang Y-S, Cho S-H. Epidemiology of adult asthma in Asia: toward a better understanding. Asia Pac Allergy. 2014;4(2):75-85.

10. Eijkemans M, Mommers M, Draaisma JMT, Thijs C, Prins MH. Physical activity and asthma: a systematic review and meta-analysis. PLoS One. 2012;7(12):e50775.

11. Benet M, Varraso R, Kauffmann F, Romieu I, Anto JM, Clavel-Chapelon F, Garcia-Aymerich J. The effects of regular physical activity on adult-onset asthma incidence in women. Respir Med. 2011:105(7):1104-7.

12. Lieberoth S, Backer V, Kyvik KO, Skadhauge LR, Tolstrup JS, Gronbaek M, Linneberg A, Thomsen SF. Intake of alcohol and risk of adult-onset asthma. Respir Med. 2012;106(2):184-8.

13. Langhammer A, Johnsen R, Gulsvik A, Holmen TL, Bjermer L. Sex differences in lung vulnerability to tobacco smoking. Eur Respir J. 2003;21(6):1017-23.

14. Roh D, Lee DH, Lee SK, Kim SW, Kim SW, Cho JH, Kim BG, Shin JH. Sex difference in IgE sensitization associated with alcohol consumption in the general population. Sci Rep. 2019;9(1):12131

15. Wang L, Wang K, Gao X, Paul TK, Cai J, Wang Y. Sex difference in the association between obesity and asthma in U.S. adults: findings from a national study. Respir Med. 2015;109(8):955-62.

16. Beckett WS, Jacobs DR Jr, Yu X, Iribarren C, Williams OD. Asthma is associated with weight gain in females but not males, independent of physical activity. Am J Respir Crit Care Med. 2001;164(11):2045-50.

17. Camargo CA Jr, Weiss ST, Zhang S, Willett WC, Speizer FE. Prospective study of body mass index, weight change, and risk of adult-onset asthma in women. Arch Intern Med. 1999;159(21):2582-8.

18. Chen $Y$, Dales $R$, Tang $M$, Krewski D. Obesity may increase the incidence of asthma in women but not in men: longitudinal observations from the Canadian National Population Health Surveys. Am J Epidemiol. 2002;155(3): $191-7$.

19. Guerra S, Sherrill DL, Bobadilla A, Martinez FD, Barbee RA. The relation of body mass index to asthma, chronic bronchitis, and emphysema. Chest. 2002:122(4):1256-63.

20. Romieu I, Avenel V, Leynaert B, Kauffmann F, Clavel-Chapelon F. Body mass index, change in body Silhouette, and risk of asthma in the E3N cohort study. Am J Epidemiol. 2003;158(2):165-74.

21. Shaheen SO, Sterne JAC, Montgomery SM, Azima H. Birth weight, body mass index and asthma in young adults. Thorax. 1999;54(5):396-402.

22. Huovinen E, Kaprio J, Koskenvuo M. Factors associated to lifestyle and risk of adult onset asthma. Respir Med. 2003;97(3):273-80.

23. Gunnbjornsdottir MI, Omenaas E, Gislason T, Norrman E, Olin AC, Jogi R, Jensen EJ, Lindberg E, Bjornsson E, Franklin K, et al. Obesity and nocturnal gastro-oesophageal reflux are related to onset of asthma and respiratory symptoms. Eur Respir J. 2004;24(1):116-21.

24. Nystad W, Meyer HE, Nafstad P, Tverdal A, Engeland A. Body mass index in relation to adult asthma among 135,000 Norwegian men and women. Am J Epidemiol. 2004;160(10):969-76.

25. Xu B, Pekkanen J, Laitinen J, Jarvelin MR. Body build from birth to adulthood and risk of asthma. Eur J Pub Health. 2002;12(3):166-70.

26. Hjellvik V, Tverdal A, Furu K. Body mass index as predictor for asthma: a cohort study of 118,723 males and females. Eur Respir J. 2010;35(6):1235-42.

27. Rönmark $E$, Andersson $C$, Nyström $L$, Forsberg $B$, Järvholm B, Lundbäck B. Obesity increases the risk of incident asthma among adults. Eur Respir J. 2005:25(2):282-8.

28. Shuster A, Patlas M, Pinthus JH, Mourtzakis M. The clinical importance of visceral adiposity: a critical review of methods for visceral adipose tissue analysis. Br J Radiol. 2012;85(1009):1-10. 
29. Kyle UG, Genton L, Hans D, Karsegard L, Slosman DO, Pichard C. Age-related differences in fat-free mass, skeletal muscle, body cell mass and fat mass between 18 and 94 years. Eur J Clin Nutr. 2001;55(8):663-72.

30. Shah RV, Murthy VL, Abbasi SA, Blankstein R, Kwong RY, Goldfine AB, Jerosch-Herold M, Lima JAC, Ding J, Allison MA. Visceral adiposity and the risk of metabolic syndrome across body mass index: the MESA study. J Am Coll Cardiol Img. 2014;7(12):1221-35.

31. Bergman RN, Kim SP, Catalano K, Hsu IR, Chiu JD, Kabir M, Hucking K, Ader M: Why visceral fat is bad: mechanisms of the metabolic syndrome. Obesity (Silver Spring, Md) 2006, 14 Suppl 1:16s-19s.

32. Janssen I, Heymsfield SB, Allison DB, Kotler DP, Ross R. Body mass index and waist circumference independently contribute to the prediction of nonabdominal, abdominal subcutaneous, and visceral fat. Am J Clin Nutr. 2002;75(4):683-8.

33. Despres JP, Prud'homme D, Pouliot MC, Tremblay A, Bouchard C. Estimation of deep abdominal adipose-tissue accumulation from simple anthropometric measurements in men. Am J Clin Nutr. 1991:54(3):471-7.

34. Kim HS, Shin DW, Lee WC, Kim YT, Cho B. National Screening Program for transitional ages in Korea: a new screening for strengthening primary prevention and follow-up care. J Korean Med Sci. 2012;27(Suppl):S70-5.

35. Litonjua AA, Sparrow D, Celedon JC, DeMolles D, Weiss ST. Association of body mass index with the development of methacholine airway hyperresponsiveness in men: the normative aging study. Thorax. 2002;57(7):581-5.

36. Kronander UN, Falkenberg M, Zetterstrom O. Prevalence and incidence of asthma related to waist circumference and BMI in a Swedish community sample. Respir Med. 2004;98(11):1108-16.

37. Brumpton B, Langhammer A, Romundstad P, Chen Y, Mai XM. General and abdominal obesity and incident asthma in adults: the HUNT study. Eur Respir J. 2013;41(2):323-9.

38. Leone N, Courbon D, Berr C, Barberger-Gateau P, Tzourio C, Alperovitch A, Zureik M: Abdominal obesity and late-onset asthma: cross-sectional and longitudinal results: the 3C study. Obesity (Silver Spring, Md) 2012, 20(3): 628-635.

39. Von Behren J, Lipsett M, Horn-Ross PL, Delfino RJ, Gilliland F, McConnell R, Bernstein L, Clarke CA, Reynolds P. Obesity, waist size, and prevalence of current asthma in the California teachers study cohort. Thorax. 2009;64(10):889.

40. Seong SC, Kim Y-Y, Park SK, Khang YH, Kim HC, Park JH, Kang H-J, Do C-H, Song J-S, Lee E-J, et al. Cohort profile: the National Health Insurance Service-National Health Screening Cohort (NHIS-HEALS) in Korea. BMJ Open. 2017;7(9).

41. Dombkowski KJ, Lamarand K, Dong S, Perng W, Clark SJ. Using Medicaid claims to identify children with asthma. Journal of public health management and practice : JPHMP. 2012;18(3):196-203.

42. Consultation WE. Appropriate body-mass index for Asian populations and its implications for policy and intervention strategies. Lancet. 2004; 363(9403):157-63.

43. Yoon YS, Oh SW. Optimal waist circumference cutoff values for the diagnosis of abdominal obesity in korean adults. Endocrinology and metabolism (Seoul, Korea). 2014;29(4):418-26.

44. Gershon AS, Guan J, Wang C, To T. Trends in asthma prevalence and incidence in Ontario, Canada, 1996-2005: a population study. Am J Epidemiol. 2010;172(6):728-36.

45. Jain R, Ray JM, Pan JH, Brody SL. Sex hormone-dependent regulation of cilia beat frequency in airway epithelium. Am J Respir Cell Mol Biol. 2012;46(4): 446-53.

46. Tantisira KG, Colvin R, Tonascia J, Strunk RC, Weiss ST, Fuhlbrigge AL. Airway responsiveness in mild to moderate childhood asthma: sex influences on the natural history. Am J Respir Crit Care Med. 2008;178(4):325-31.

47. Schatz M, Camargo CA Jr. The relationship of sex to asthma prevalence, health care utilization, and medications in a large managed care organization. Annals of allergy, asthma \& immunology : official publication of the American College of Allergy, Asthma, \& Immunology. 2003;91(6):553-8.

48. Troisi RJ, Speizer FE, Willett WC, Trichopoulos D, Rosner B. Menopause, postmenopausal estrogen preparations, and the risk of adult-onset asthma. A prospective cohort study. Am J Respir Crit Care Med. 1995;152(4 Pt 1): 1183-8

49. Beuther DA, Sutherland ER. Overweight, obesity, and incident asthma: a meta-analysis of prospective epidemiologic studies. Am J Respir Crit Care Med. 2007;175(7):661-6.

50. Ford ES. The epidemiology of obesity and asthma. J Allergy Clin Immunol. 2005;115(5):897-909 quiz 910.
51. Kim S-H, Sutherland ER, Gelfand EW. Is there a link between obesity and asthma? Allergy, Asthma Immunol Res. 2014;6(3):189-95.

52. Ouchi N, Parker JL, Lugus JJ, Walsh K. Adipokines in inflammation and metabolic disease. Nat Rev Immunol. 2011;11(2):85-97.

53. Salah A, Ragab M, Mansour W, Taher M. Leptin and adiponectin are valuable serum markers explaining obesity/bronchial asthma interrelationship. Egyptian J Chest Diseases Tuberculosis. 2015;64(3):529-33.

54. Gruchala-Niedoszytko M, Malgorzewicz S, Niedoszytko M, Gnacinska M, Jassem $E$. The influence of obesity on inflammation and clinical symptoms in asthma. Advances med sci. 2013;58(1):15-21.

55. Farah CS, Salome CM. Asthma and obesity: a known association but unknown mechanism. Respirology (Carlton, Vic). 2012;17(3):412-21.

56. Boulet L-P, Boulay M-Ė. Asthma-related comorbidities. Expert Rev Respiratory Med. 2011;5(3):377-93.

57. Kwon JW, Kim SH, Kim TB, Kim SH, Park HW, Chang YS, Jang AS, Cho YS, Nahm DH, Park JW, et al. Airway hyperresponsiveness is negatively associated with obesity or overweight status in patients with asthma. Int Arch Allergy Immunol. 2012;159(2):187-93.

58. Onat A, Avci GS, Barlan MM, Uyarel H, Uzunlar B, Sansoy V. Measures of abdominal obesity assessed for visceral adiposity and relation to coronary risk. Int j obesity related metabolic disorders : j Int Association Study Obesity. 2004;28(8):1018-25.

59. Kuk JL, Lee S, Heymsfield SB, Ross R. Waist circumference and abdominal adipose tissue distribution: influence of age and sex. Am J Clin Nutr. 2005; 81(6):1330-4.

60. Polosa R, Thomson NC. Smoking and asthma: dangerous liaisons. Eur Respir J. 2013;41(3):716-26.

61. Piipari R, Jaakkola JJK, Jaakkola N, Jaakkola MS. Smoking and asthma in adults. Eur Respir J. 2004;24(5):734-9.

62. Thomson NC, Chaudhuri R, Livingston E. Asthma and cigarette smoking. Eur Respir J. 2004:24(5):822-33.

63. Miravitlles M, Andreu I, Romero Y, Sitjar S, Altés A, Anton E. Difficulties in differential diagnosis of COPD and asthma in primary care. Br J Gen Pract. 2012;62(595):e68-75.

64. Korean statistical information service (KOSIS). Obesity prevalence: by sex adults aged 19 years and older. 2017 http://kosis.kr/statHtml/statHtml. do? orgld=117\&tblld=DT_11702_N101\&vw_cd=MT_ZTITLE\&list_id=117_11 702_B01\&seqNo=\&lang_mode $=$ ko\&language $=$ kor\&obj_var_id $=\& i t m \_i d=$ \&conn_path=MT_ZTITLE. Accessed 18 Nov 2019.

65. Newell SA, Girgis A, Sanson-Fisher RW, Savolainen NJ. The accuracy of selfreported health behaviors and risk factors relating to cancer and cardiovascular disease in the general population: a critical review. Am J Prev Med. 1999;17(3):211-29.

66. Connor Gorber S, Schofield-Hurwitz S, Hardt J, Levasseur G, Tremblay M. The accuracy of self-reported smoking: a systematic review of the relationship between self-reported and cotinine-assessed smoking status. Nicotine tobacco res : official j Soc Res Nicotine Tobacco. 2009;11(1):12-24.

\section{Publisher's Note}

Springer Nature remains neutral with regard to jurisdictional claims in published maps and institutional affiliations.

Ready to submit your research? Choose BMC and benefit from:

- fast, convenient online submission

- thorough peer review by experienced researchers in your field

- rapid publication on acceptance

- support for research data, including large and complex data types

- gold Open Access which fosters wider collaboration and increased citations

- maximum visibility for your research: over $100 \mathrm{M}$ website views per year

At $\mathrm{BMC}$, research is always in progress.

Learn more biomedcentral.com/submission 